\title{
Assessment of steel mechanical characteristics of non-standard compact specimens under statistical tests
}

\author{
Rim N. Khasanov ${ }^{1}$, Aybulat S. Valiev ${ }^{1, *}$, and Iskander Kuzeev ${ }^{1}$ \\ ${ }^{1}$ FSBEI of Higher Education "Ufa State Petroleum Technological University" \\ Ufa, the Russian Federation
}

\begin{abstract}
It is necessary to evaluate possible changes of mechanical characteristics while determining reasons of equipment destruction as a result of implementation of emergency situation. Limited amount of the material collected at the local fracture point requires the use of compact testing specimens. Practical implementation of the method requires establishment of dependence setting correlation between characteristics which were determined under the standard method and the method that uses compacts specimens. In the present research as exemplified by the steel 20 for recalculation of values of yield limit determined by different methods.
\end{abstract}

\section{Introduction}

It is specified in the works [1-3] that in cases of determining reasons of equipment destruction as a result of implementation of emergency situations it is hard to use standard specimens for determination of constructional material mechanical properties. Therefore, it is currently important to use compact specimens that need the smallest amount of test material [5]. It should be mentioned that the majority of characteristics of steel mechanical properties are not physical constants and their values depend on test conditions. Besides the test results will be affected by damages accumulated in metal due to operation conditions and emergency implementation.

\section{Experimental procedure. Statistical tests}

Present researches are intended to specify the type of influence of the indicated factors on fracture work. Cyclic tests on the chassis dynamometer Instron 8801(Fig.1) were conducted on the cylindrical specimens made of steel 20.

\footnotetext{
* Corresponding author: valiev16101994@yandex.ru
} 


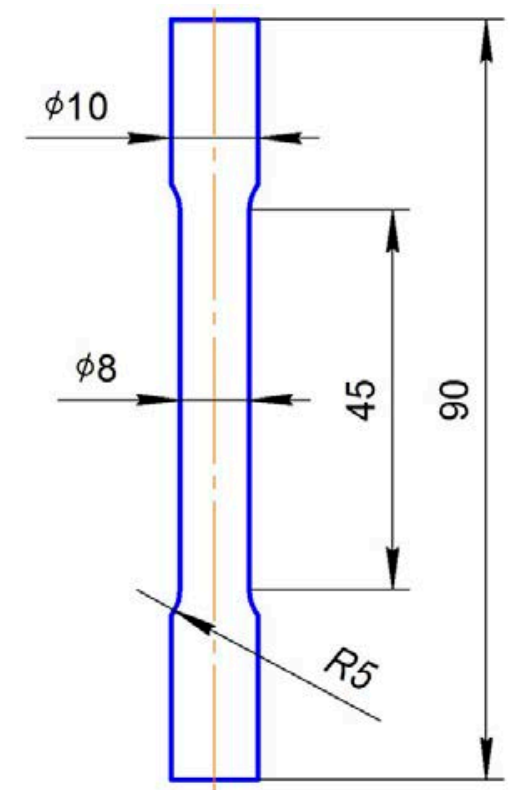

a. Dimensions of cylindrical specimens

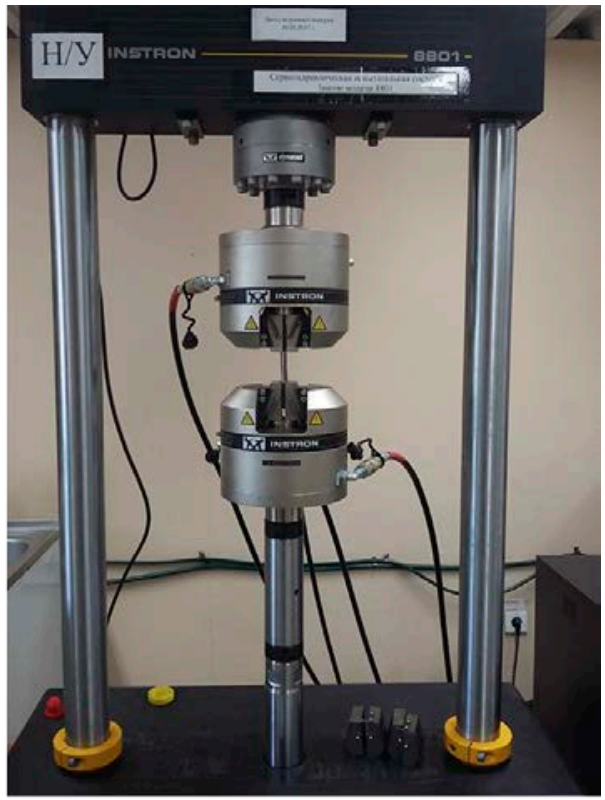

b. Tension test of cylindrical specimen

Fig. 1. Characteristics of test specimens and testing equipment

Tension test diagram for yield limit determination is illustrated in Fig.2. The yield limit of the test steel was $389 \mathrm{MPa}$

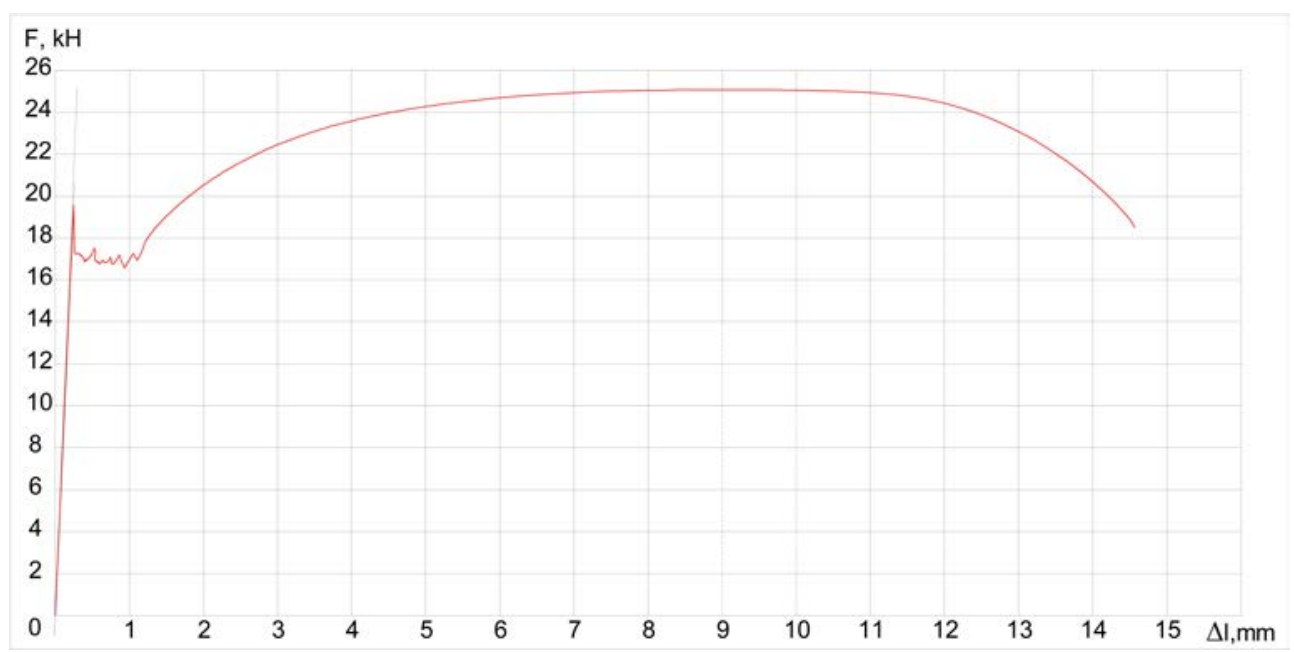

Fig. 2. Tension diagram of initial specimen made of steel 20

For determination of values correlation of metal mechanical characteristics received on standard and compact specimens. Compact specimens were made from standard specimens as shown in Fig.3. 

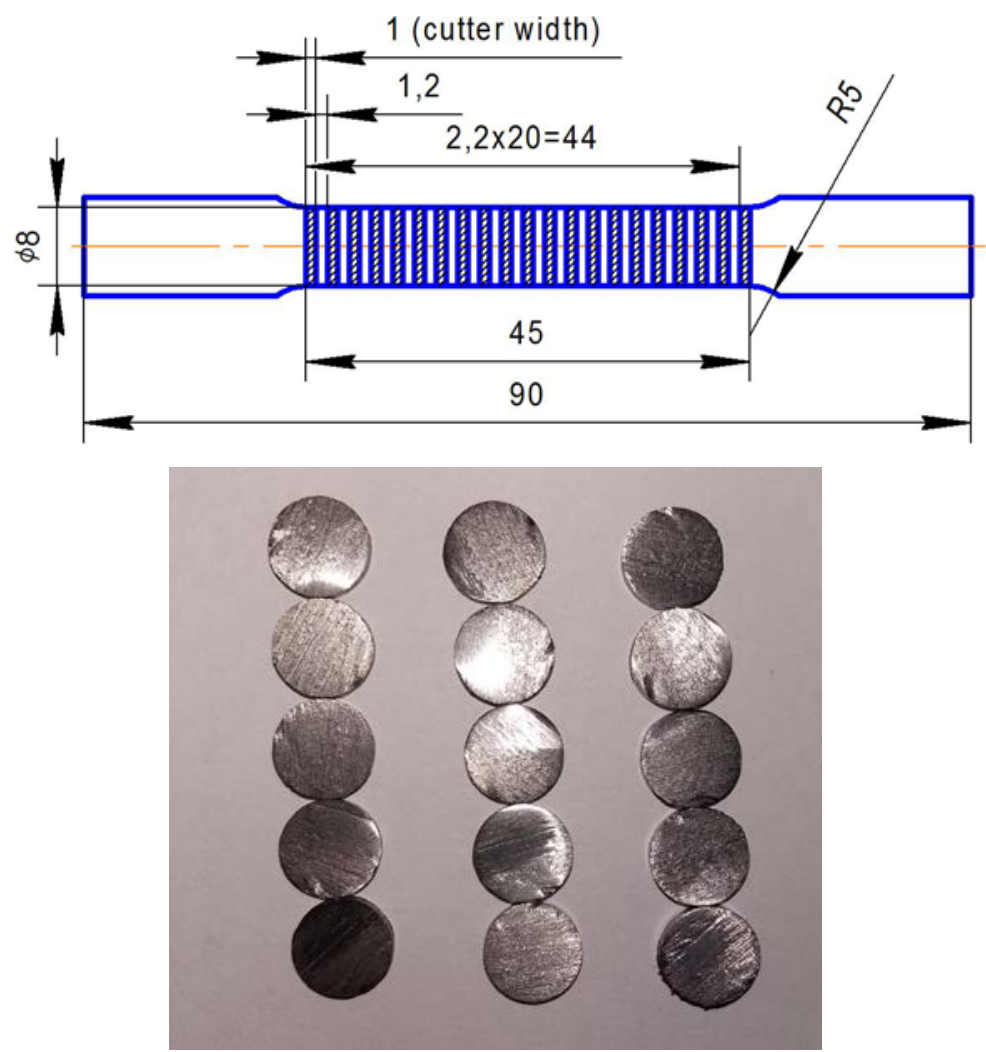

Fig. 3. Compact specimens obtained upon cutting standard specimens.

Four sizes $(0.6,0.8,1.0,1.2 \mathrm{~mm})$ of compact specimens' thickness were set. Moreover the last values were determined immediately upon cutting the cylindrical specimen, first two specimens were polished till necessary sizes.

A tool consisting of contact point and housing, in which a compact specimen is inserted and fastened with special cap, was made for testing of compact specimens. Deformation was conducted with minimum perforation speed $\mathrm{v}=0,2 \mathrm{~mm} / \mathrm{min}$ using a punch with $2.5 \mathrm{~mm}$ in diameter hemispherical head (Fig.4). Tests were considered to be finished upon decrease of maximum load till $40 \%$.
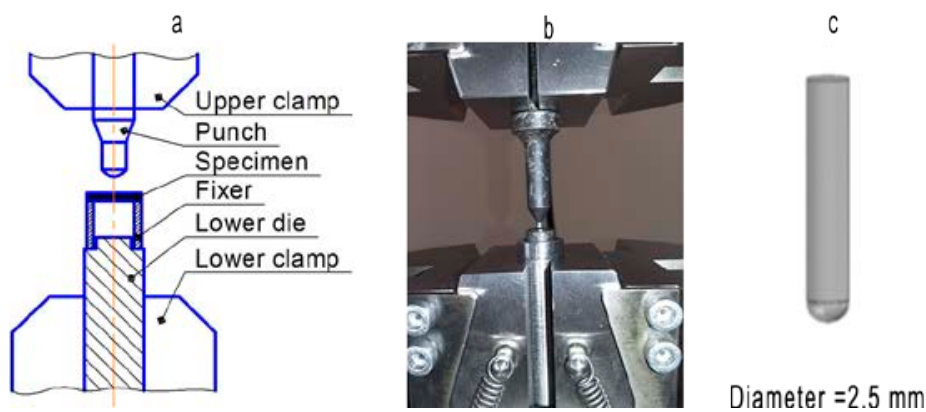

d

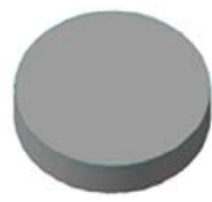

Diameter: $8 \mathrm{~mm}$ Thickness: $0.6-1.2 \mathrm{~mm}$

a) test circuit; b) general view of the test tool

c) test contact point, d) cylindrical compact specimen

Fig. 4. Constructional elements for testing of compact specimens 
Zoning suggested in the work [4] was used for analysis of the obtained diagrams: Zone I (elastic deformation), zone II (elastoplastic transition), zone III (generalized plastic deformation), zone IV (plastic instability and fracture propagation), zone V (fractures softening zone) and zone VI (final fracture (fig. 5).

Following parameter identifiers are used for diagram analysis: $\sigma^{1}$ - compact specimens yield limit in zone I (elastic deformation zone); $\sigma^{2}$ - compact specimens yield limit in zone II (transition zone); $\mathrm{ki}^{1}$ - scaling coefficient for zone I (elastic deformation zone); $\mathrm{ki}^{2}{ }^{2}$ scaling coefficient for zone II (transition zone); $\mathrm{S}$-punch area equal to $3,14 \mathrm{~mm}^{2}$.

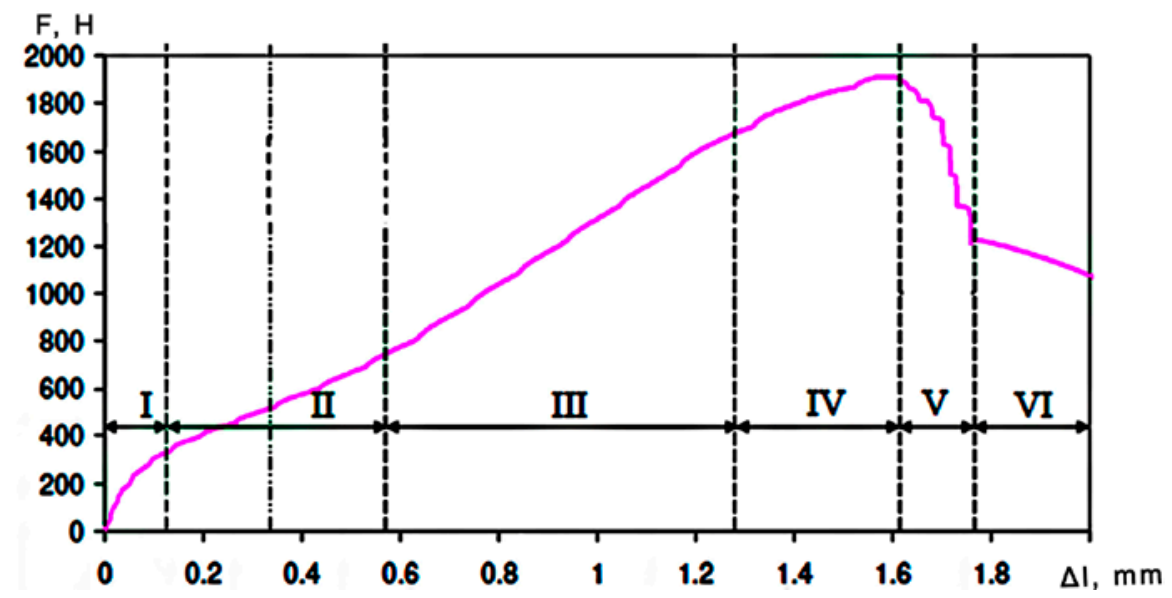

Fig. 5. Zoning of compact specimens fracture diagram [4] (identifiers are indicated in the text).

The first series of tests is devoted to obtaining correlation dependences between steel 20 mechanical characteristics determined on standard specimens and compact specimens under tension fracture. Three specimens were tested: the first one was used for standard test and two others were cut to compact specimens.

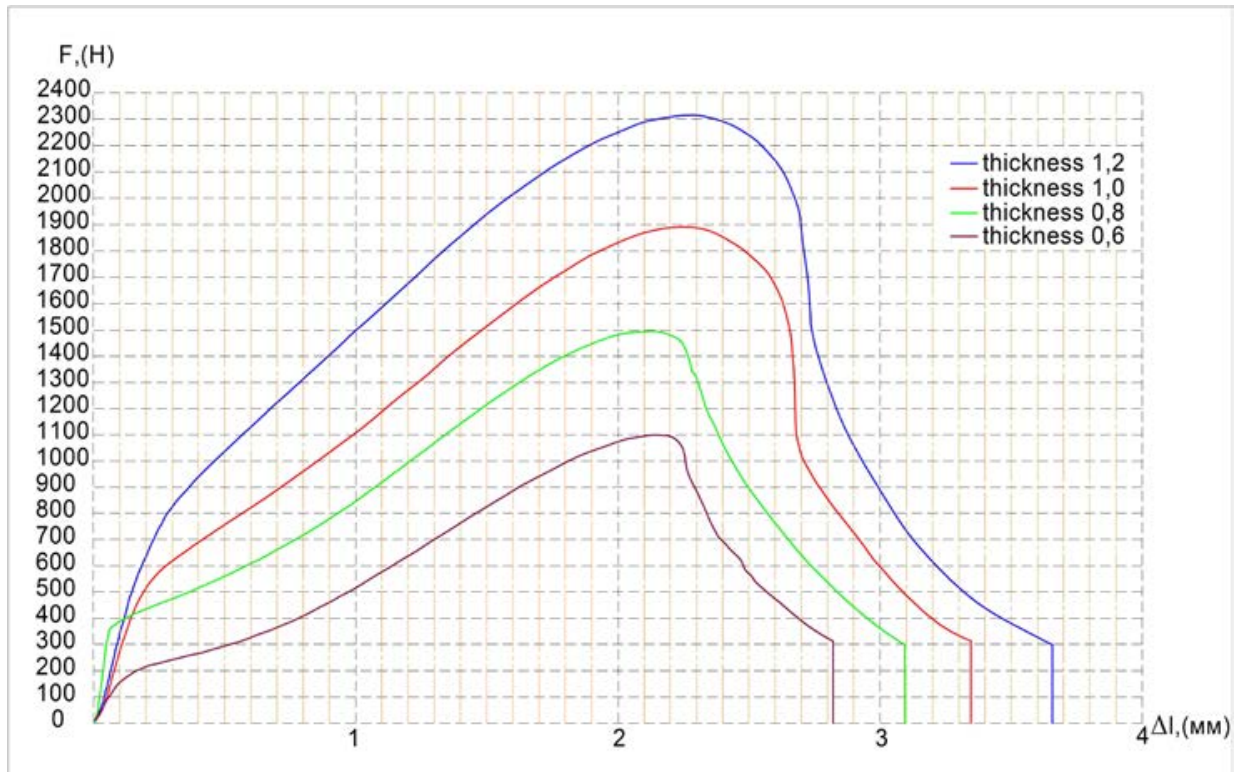

Fig. 6. Comparative fracture diagrams of compact specimens of different thickness (the first macrospecimen) 


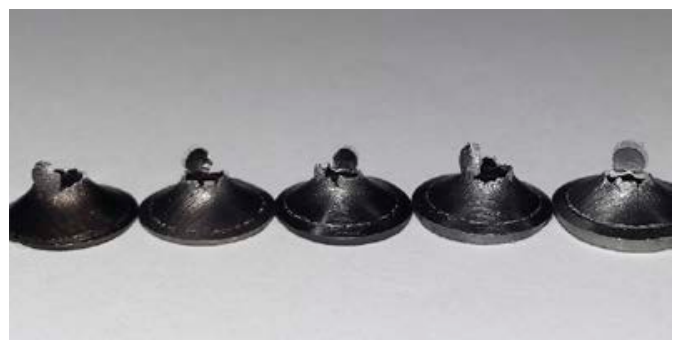

Fig. 7. Tested specimens of the first series

Diagram processing enabled to obtain fracture work values for specimens of different thickness that are indicated in the table 1.

Table 1. Work done during fracture of compact specimens

\begin{tabular}{|c|c|}
\hline Specimen thickness, $\mathbf{m m}$ & Work, $\mathbf{H}^{*} \mathbf{m m}[\mathbf{J}]$ \\
\hline 0.6 & $1678.8[1.68]$ \\
\hline 0.8 & $2749.6[2.75]$ \\
\hline 1.0 & $3804.2[3.8]$ \\
\hline 1.2 & $5165.5[5.16]$ \\
\hline
\end{tabular}

Table 2. Mechanical properties and scaling coefficients (first macrospecimen

\begin{tabular}{|c|c|c|c|c|}
\hline \multicolumn{5}{|c|}{ Zone I (elastic deformation) } \\
\hline № & $\begin{array}{c}\mathbf{h}, \\
\mathbf{m m}\end{array}$ & $\begin{array}{c}\mathbf{\sigma}_{\mathbf{r}}, \\
\mathbf{M P a}\end{array}$ & $\begin{array}{c}\mathbf{\sigma}^{\mathbf{1}}, \\
\mathbf{M P a}\end{array}$ & $\mathbf{k i}^{\mathbf{1}}$ \\
\hline 1 & 0.6 & 389 & 76.4 & 5 \\
\hline 2 & 0.8 & 389 & 143.3 & 2.7 \\
\hline 3 & 1.0 & 389 & 181.5 & 2.1 \\
\hline 4 & 1.2 & 389 & 229.9 & 1.7 \\
\hline
\end{tabular}

\begin{tabular}{|c|c|c|c|c|}
\hline \multicolumn{5}{|c|}{ Zone II (transition zone) } \\
\hline № & $\begin{array}{c}\mathbf{h}, \\
\mathbf{m m}\end{array}$ & $\begin{array}{c}\mathbf{\sigma}_{\text {T }}, \\
\mathbf{M P a}\end{array}$ & $\begin{array}{c}\boldsymbol{\sigma}^{\mathbf{2}}, \\
\mathbf{M P a}\end{array}$ & $\mathbf{k i}^{\mathbf{2}}$ \\
\hline 1 & 0.6 & 389 & 162.4 & 2.4 \\
\hline 2 & 0.8 & 389 & 270.7 & 1.4 \\
\hline 3 & 1.0 & 389 & 350.3 & 1.1 \\
\hline 4 & 1.2 & 389 & 477.7 & 0.8 \\
\hline
\end{tabular}

Repetitive experiments conducted after cutting of the second specimen showed results indicated in Fig. 8.

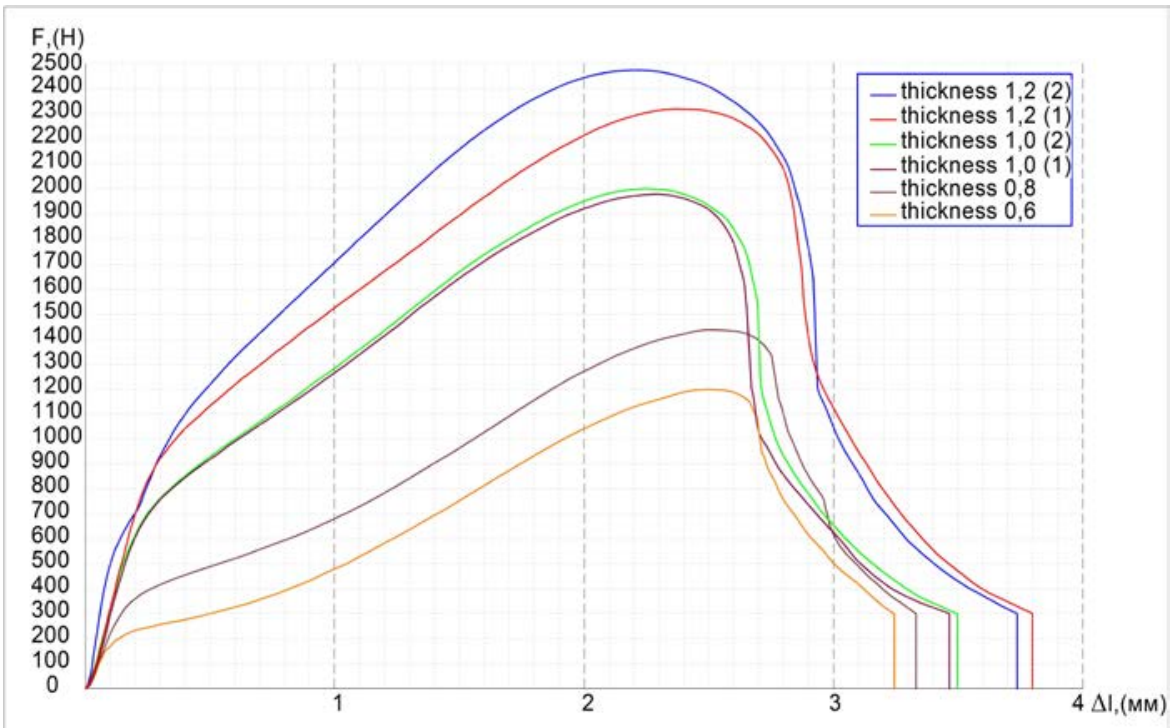

Fig. 8. Comparative fracture diagrams of compact specimens of different thickness (the second macrospecimen) 
Table 3. Scaling coefficients and mechanical properties (the second macrospecimen)

\begin{tabular}{|c|c|c|c|c|}
\hline \multicolumn{5}{|c|}{ Zone I (elastic deformation) } \\
\hline $\mathbf{N} N$ & $\begin{array}{c}\mathbf{h}, \\
\mathbf{m m}\end{array}$ & $\begin{array}{c}\boldsymbol{\sigma}_{\text {T }}, \\
\mathbf{M P a}\end{array}$ & $\begin{array}{c}\mathbf{\sigma}^{\mathbf{3}}, \\
\mathbf{M P a}\end{array}$ & $\mathbf{k i}^{\mathbf{3}}$ \\
\hline 1 & 0.6 & 389 & 80 & 4.9 \\
\hline 2 & 0.8 & 389 & 141.8 & 2.7 \\
\hline 3 & 1.0 & 389 & 283.4 & 1.4 \\
\hline 4 & 1.2 & 389 & 359.9 & 1.1 \\
\hline
\end{tabular}

\begin{tabular}{|c|c|c|c|c|}
\hline \multicolumn{5}{|c|}{ Zone II (transition zone) } \\
\hline № & $\begin{array}{c}\mathbf{h}, \\
\mathbf{m m}\end{array}$ & $\begin{array}{c}\boldsymbol{\sigma}^{\mathbf{T}}, \\
\mathbf{M P a}\end{array}$ & $\begin{array}{c}\boldsymbol{\sigma}^{\mathbf{4}}, \\
\mathbf{M P a}\end{array}$ & $\mathbf{k i}^{\mathbf{4}}$ \\
\hline 1 & 0.6 & 389 & 130.6 & 3 \\
\hline 2 & 0.8 & 389 & 210.2 & 1.9 \\
\hline 3 & 1.0 & 389 & 473 & 0.8 \\
\hline 4 & 1.2 & 389 & 566.9 & 0.7 \\
\hline
\end{tabular}

According to the analysis of data from tables 3 and 4 the results of identical specimens can vary within $0-35 \%$ that requires implementation of enormous amount of tests and statistical processing of results.

\section{Conclusions}

Comparative tests of standard and compact specimens made of steel 20 demonstrated possibility of mechanical characteristics determination when using compact specimens of different thickness. The tests enabled to determine the scaling coefficients for transition to actual steel yield limit values. At the same time the researches showed that there is a spread in the measured values during two series of identical tests, that in future will require the increase of the amount of tests for full statistical processing of the obtained results.

\section{References}

1. R.N. Khasanov, Use of compact specimens for determination of constructional materials mechanical properties, USPTU young scientist bulletin, №1, pp. 5-11 (2016)

2. R.N. Khasanov, V.A. Gafarova, M.R. Abdulganiev, I.R. Kuzeev, Assessment of mechanical properties of constructional materials with the use of compact specimens, Modern methods and tools of diagnostics of electric and electrotechnical equipment, automation means and systems; materials of Russian National Science and Technology Conference, pp. 268-269 (2016)

3. R.N. Khasanov, A.A. Ryabov, I.R. Kuzeev, Dete rmination of fracture work on compact steel specimens, Problems of gathering, processing and transportation of crude oil and petroleum products, E 1 (107), pp. 116-123 (2017)

4. Numerical Simulations. Applications, Examples and Theory. Edited by Lutz Angermann (InTech, 2011)

5. D.A. Collins, Damage of materials in constructions. Analysis, prognosis, damage control. Study guide (MIR, 1984) 